\title{
Optimal Power Dispatch of WECS and UPFC with ACO and ANFIS Algorithms
}

\author{
Sunny Vig and Balwinder Singh Surjan \\ PEC University of Technology, Chandigarh. \\ sunnyv0417@gmail.coms
}

\begin{abstract}
Wind energy conversion systems are the quickest developing renewable source of electrical energy having tremendous environmental and social advantages. In this paper proposed an optimal reactive power dispatch (ORPD) technique of wind power plants in grid connected power system. The ORPD issue is a vital issue in the operation of power frameworks. It is a nonlinear and mixed integer programming issue, which decides ideal qualities for control parameters of reactive power makers to upgrade particular target capacities while fulfilling a few specialized requirements. The ORPD technique consists of ACO and ANFIS controller for improving the performance of multiple wind turbines and the steady state stability of the power system in terms of active and reactive power flow of a transmission line. The ACO algorithm is used to extract the maximum power from WECS. The generated maximum power is transmitted through the UPFC connected HVDC link. The performance of the UPFC is improved with the ANFIS controller based on the actual and the reference power parameters of the grid connected power system. Furthermore, UPFC is utilized to control active and reactive flow of power in a transmission line. The proposed method is implemented in MATLAB/Simulink platform and tested with the different wind speed condition. To verify the effectiveness of the proposed model, the obtained results in the deterministic case is compared with the existing methods like GA and PSO.
\end{abstract}

Keywords: Unified Power Flow Controller (UPFC), Ant Colony Optimization (ACO) Algorithm, Adaptive Neuro Fuzzy Inference System (ANFIS), wind energy conversion system (WECS) and power quality (PQ).

\section{Introduction}

The fast development of power system leads to increase in demand of electricity which leads to different technical problems like PQ and stability [1]. One of the most popular ways of generating electricity from renewable sources is to use wind turbines [2]. Wind energy is efficient and promising renewable energy resources in the world which is continuously growing with the increase of electrical power demand and the decrease in conventional electricity generation resources $[3,4]$. At the present time and in the near future, generators for wind turbines will synchronous generators, permanent magnet synchronous generators and induction generators [5]. To maintain the operability along with reliability and power quality of the grid, WECS are integrated with the power grids rather operating standalone. The grid code requirements are of two types: static and dynamic requirements. Static requirements include steady state behavior and power flow at the point of common coupling (PCC) whereas dynamic grid code requirement includes the desired responses of the induction generator during grid disturbances [6]. These requirements include the operating range of voltage and frequency grid-support capability, regulation of power factor, and fault ride-through (FRT) capability [7]. According to the wind turbine, Power quality issue is one of the major concerns in the distribution network [8]. It is a measure of the standard of delivered power. By delivering low quality electric power to the consumer, it could affect the accuracy of utility metering; cause malfunction to protective relays; cause destructive damage to equipment and others. From 
research findings, power system monitoring, inverter, dynamic voltage regulator (DVR), static synchronous compensator (STATCOM), unified power quality conditioner (UPQC), and energy storage system are approaches that are used in alleviating power quality issues [9]. A UPFC is an electrical device for providing fast-acting reactive power compensation on high voltage electricity transmission networks [10]. UPFC provides power flow control together with independent voltage control. The main disadvantage of this device is the high cost level due to the complex system setup [11]. By controlling the UPFC as a virtual inductor, we aim to increase the voltage at the terminals of the WECS and thereby mitigate the destabilizing electrical torque and power during the fault [12].

The impacts of wind power on power quality, the gird requirements for integration of wind turbines, and discussed the potential operation and control methods to meet the challenges [13]. To minimize the PQ issues in wind turbine framework, numerous sorts of power transformation system to be associated between the generator and grid lines $[14,15]$. The ORPD problem is a vital issue in the operation of power frameworks. It is a nonlinear and mixed integer programming issue, which decides ideal qualities for control parameters of reactive power makers to upgrade particular target capacities while fulfilling a few specialized requirements $[16,17]$. For solving this issue, traditional methods are utilized, such as, varies MPPT algorithm like Hill climbing search (HCS), incremental conductance (INC) and optimum relation based (ORB), perturb and disturb (P\&O) algorithm, soft computing based MPPT Fuzzy Logic Controller, Cuckoo Search Algorithm, Fuzzy logic [18, 19], Artificial Neural Network and Artificial Bee colony algorithm are adopted. Recently, the intelligent search based optimization algorithms like seeker optimization algorithm (SOA), Genetic Algorithm (GA), Particle swarm optimization algorithm (PSO), harmony search algorithm, differential evolutionary based method, and gravitational search algorithm (GSA) have been created to manage the ORPD issue [20].

In perception of these issues, ORPD issue is a vital issue in the operation of power frameworks. It is a nonlinear and mixed integer programming issue, which decides ideal qualities for control parameters of reactive power makers to upgrade particular target capacities while fulfilling a few specialized requirements. In the ORPD issue, intelligent search based optimization algorithms like seeker optimization algorithm (SOA), harmony search algorithm, differential evolutionary based method, and GSA have been created to manage the ORPD issue. However, there are a few specialized issues emerging from compensation techniques and the unpredictability of control operation. The recent research works are presented in Section 2 and the detailed description of the proposed technique is presented in Section 3. The experimental results and discussion are given in Section 4. Finally, the Section 5 concludes the paper.

\section{Recent Research Works: A Brief Review}

Numerous related works are already existed in literature which based on Wind energy conversion system based grid for analyzing the power flow. Some of them reviewed here.

Joan Sau-Bassols et al. [21] have presented a series tapping station for integrating Offshore Wind Power Plants (OWPP) into a (Line Commutated Converter High Voltage Direct Current) LCC-HVDC transmission system. The tapping station allowed integrating the wind power resources without building a HVDC link and it was based on a Current Source Converter (CSC). However, the CSC requires a minimum DC current to extract the power coming from the OWPP which may not be guaranteed depending on the power conditions of the HVDC corridor. In the reason, that paper proposed a coordinated operation and control of the CSC and the OWPP. A steady-state analysis was performed to determine the appropriate AC voltage level of the CSC. A power reduction algorithm was presented to limit power extraction during a reduction in the current of the HVDC transmission system and under loss of communications between the CSC and the OWPP. 
Fernando D. Bianchi et al. [22] have implemented a coordinated control scheme in order that offshore WPPs connected through multi-terminal HVDC systems were able to contribute to the primary frequency control of the land AC grids. The proposed control scheme was capable of achieving a suitable frequency regulation even under low wind power conditions by allowing also the power share among AC areas. The control scheme was evaluated by dynamic simulations in an adapted version of the Cigr DC grid benchmark with a five-terminal HVDC grid including two wind farms and three AC networks.

Chayan Bhattacharjee et al. [23] have developed an intelligent extraction of optimum power and its dispatch by using fuzzy logic from a grid tied hybrid generation system comprising of a permanent magnet synchronous generator based wind turbine and a low concentration photovoltaic generator. For photovoltaic generator, maximum power point tracking control was implemented using fuzzy logic under varying solar irradiance. Power extracted from wind turbine was designed as a fuzzy function of the dc link voltage error, its rate of change and error in the direct axis current of the inverter. That reduces high frequency oscillations in the wind extracted power. A failure mode and effect analysis was done for power converters and possible mitigation schemes were suggested for different faults.

Asit Mohanty et al. [24] have presented a comparative study of transient stability and reactive power compensation issues in an autonomous wind-diesel-photovoltaic based hybrid system (HS) using robust fuzzy-sliding mode based UPFC. A linearize small-signal model of the different elements of the HS was considered for the transient stability analysis in the HS under varying loading conditions. An IEEE type 1 excitation system was considered for the synchronous generator in the HS, with negligible saturation characteristic, for detailed voltage stability analysis. It was noted from the simulation results that the performance of UPFC was superior to static VAR compensator and static synchronous compensator in improving the voltage profile of the HS. Further, fuzzy and fuzzy-sliding mode based UPFC controller was designed in order to improve the transient performance.

Rong Zeng et al. [25] have developed the control and operation of a hybrid HVDC system comprising a wind farm-side voltage-source converter rectifier and a grid-side LCC inverter for integrating wind power. The configuration and operation principle of the hybrid HVDC system were described. Commutation failure in the LCC inverter during an ac network disturbance was considered and its impact on the hybrid system operation was analyzed. An enhanced control strategy for the LCC inverter at the grid side and an alternative modular multilevel converter (MMC) topology using mixed half-bridge and full-bridge modules considered for the rectifier at the wind farm side were proposed.

Recently, wind vitality has gotten to be a standout amongst the most essential and promising wellsprings of renewable vitality, which requests extra transmission limit and better method for keeping up framework reliability. The need to coordinate the renewable energy like wind energy into power system is to make it conceivable to minimize the ecological effects. The coordination of wind energy into existing power system introduces a specialized difficulties and that requires thought of voltage regulation, stability, power quality problems like voltage sag, voltage swell, noise and harmonics. The produced power PQ is significantly influenced by operation of a transmission and distribution system. To enhance the power, effectiveness of grid connected WECS; high proficiency gadgets taking into account power hardware types of gear have been progressively utilized, for example, STATCOM, UPQC and so on. In the paper, UPFC is utilized to control active and reactive flow of power in a transmission line. It is a mix of arrangement associated Static Synchronous Series Compensator (SSSC) and shunt connected Static synchronous Compensator (STATCOM). Here, the ACO Algorithm, and ANFIS approach is employed to decide the finest compromise solution. The ACO algorithm is used to extract maximum wind power and ANFIS is utilized to enhance performance of UPFC for accomplishing the optimal results. The detailed description of the proposed method is described in the section 3. 


\section{Proposed Methodology for Multiple Wind Turbine With UPFC}

In this section discussed about the performance analysis of the proposed methodology of the wind turbine with UPFC. The proposed methodology consists of ACO and ANFIS algorithm for the steady state stability of the power system and improving the performance of multiple wind turbines. The ACO Algorithm is used as an optimizing technique to extract maximum wind power by controlling pitch angle and UPFC in Co-ordination with HVDC link is used to control active and reactive flow of power in a transmission line. The proposed controlling model is illustrated in figure 1, which consists of proposed control system and grid connected power system. The wind energy conversion system has four major components built with a wind turbine, generator, interconnection apparatus and control systems. The wind turbine operates either down-wind or up-wind. Most turbine manufacturers have opted for reduction gears between the low speed turbine rotor and the high speed three-phase generators. To generate the maximum power the ACO algorithm is used to extract the maximum power instead of MPPT algorithm. In this proposed algorithm the pitch angle is controlled and extracts the maximum power. The pitch angle is kept constant at zero degree until the speed reaches maximum speed of the tracking characteristic. The pitch angle is proportional to the speed deviation of the wind turbine speed.

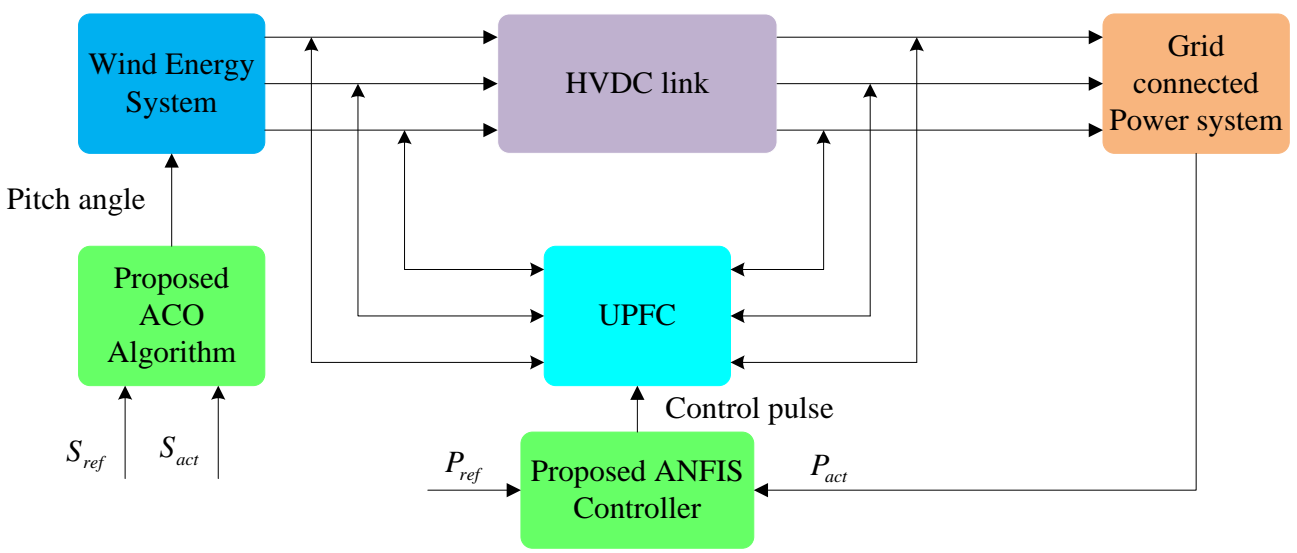

Figure 1. The proposed model for optimal power dispatch from WECS

Then the power is transmitted to grid connected power system through HVDC link. The Optimization of electric power transmission system capacity requires a reliable power flow controller. The power flow controllers must be able to control the level of electrical voltage and active and reactive power flow without reducing the level of stability and security of the transmission system. Latest technology in the control of power flow is a UPFC, which is maintaining the steady state stability of the system. UPFC consists of a combination of a shunt and series branches connected through the DC capacitor The series connected inverter injects a voltage with controllable magnitude and phase angle in series with the transmission line, therefore providing real and reactive power to the transmission line. The shunt-connected inverter provides the real power drawn by the series branch and the losses and can independently provide reactive compensation to the system. For increasing the performance of the UPFC the ANFIS algorithm is used to control the power variation of the grid connected power system. In this algorithm compensate the variations between the actual power and reference power of the power system. The modeling of the proposed model is explained in a following section. 


\section{A. Mathematical Modeling of Wind Turbine}

The wind turbine is distinguished by no dimensional curves of the power coefficient $C_{p}$ as a utility of together the tip speed ratio $\lambda$ and the blade pitch angle $\beta$. So as to completely exploit the existing wind energy, tip speed ratio should be preserved at its finest value. Consequently, the power coefficient equivalent to that value will turn out to be high. It can be distinct as the proportion of the angular rotor speed of the wind turbine to the linear wind speed at the tip of the blades [26]. It can be conveyed as equation (1),

$$
\lambda=\frac{\omega_{t} R}{V_{\omega}}
$$

In addition, the relation between $\lambda$ and $\beta$ can be found in the following equation (2),

$$
\frac{1}{\lambda_{i}}=\frac{1}{\lambda+0.08 \beta}-\frac{0.035}{\beta^{3}+1}
$$

A generic equation is used to model $C_{p}(\lambda, \beta)$. The characteristics of the wind turbine model is given as equation (3),

$$
C_{p}(\lambda, \beta)=C_{1}\left(\frac{C_{2}}{\lambda_{i}}-C_{3} \beta-C_{4}\right) e^{\frac{-C_{5}}{\lambda_{i}}}+C_{6} \lambda
$$

The mechanical power of the WT is a utility of producer speed for dissimilar wind speeds and for blade pitch angle $\beta=0$. The automatic power detained by a wind turbine in the fixed condition is specified by equation (4),

$$
P_{m}=C_{p}(\lambda, \beta) \frac{\rho A}{2} V_{\text {wind }}^{3}
$$

From the equation(4), $P_{m}$ is the automatic output power of the turbine (W), $C_{p}$ is the presentation coefficient of the turbine, $\rho$ is the air density $(\mathrm{kg} / \mathrm{m} 3), A$ is the turbine swept area (m2), $V_{\text {wind }}$ is the wind speed $(\mathrm{m} / \mathrm{s}), \lambda$ is the tip speed proportion and $\beta$ is the blade pitch angle $(\circ)$. Since on top of the equation can be standardized and in the per unit $(p u)$ scheme we have specified as equation (5),

$$
P_{m_{-} p u}=k_{p} C_{p_{-} p u} V_{\text {wind }}^{3} p u
$$

Where, $P_{m_{-} p u}$ is the power in pu derived from the ostensible power for exacting values of $\rho$ and $A, C_{p_{-} p u}$ is the presentation coefficient in pu depend on the highest value of $C_{p}$. $V_{\text {wind }_{-} p u}$ is the wind speed in pu depend on the base wind speed, $k_{p}$ is the power gain which is fewer than or identical to 1 for $C_{p_{-} p u}=1 p u$ and $V_{\text {wind }} p u=1 p u$.

\section{B. Maximization of Wind Power Generation}

The adaptation of wind energy is offered by the wind turbine and the induction generator (WTIG). The stator winding is associated openly to the network and the motor is determined by the wind turbine. The power detained by the wind turbine is transformed into electrical power by the induction generator and is conveyed to the network by the stator winding. The pitch angle is prohibited to control the producer output power to its insignificant value for elevated wind speeds. To produce power the induction producer speed must be vaguely higher than the synchronous speed. Excluding the speed dissimilarity is usually so diminutive that the WTIG is measured to be a preset speed wind generator. The immediate power immersed by the induction generator can be supplied by the network [27]. At this time, an UPFC is derived from 
the current-source converter topology is projected, which permits an optimized immediate power insertion for the duration of voltage dips take place in the network, and assist the preset speed WTIG to produce its mortal voltage. To adjust the speed derived from the pitch angle of the power scheme is depicted in subsequent segment.

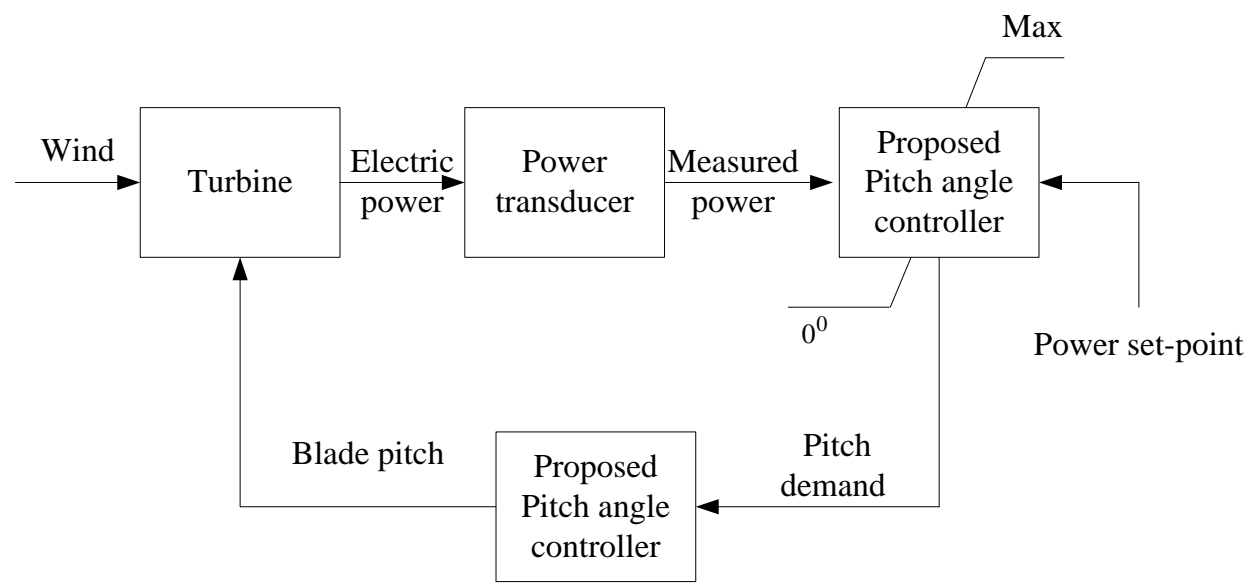

Figure 2. The control loop for regulating speed and pitch angle in WT

The foremost fundamentals of the control loop for a preset speed pitch synchronized turbine are exposed in figure 2. Generally, the Proportional-Integral (PI) controller is employed to manage the blade pitch angle to maintain the electric output power to the ostensible automatic power. The pitch angle is reserved stable at zero when the considered electric output power is below its ostensible value. The ostensible value is assessed derived from the ACO algorithm, which manage the finest explanation in non-linear environment. When it augments higher than its ostensible value the regulator augment the pitch angle to reinstate the considered power to its ostensible value [28]. Afterward the WT representation is clarified in a subsequent segment.

\section{Proposed ACO algorithm for maximum power generation}

For optimizing wind power using ACO Algorithm different parameters is considered such as rotor angle, tip speed ratio, wind speed and air density. By taking into consideration different parameters ACO as decision making tool optimal value of wind speed where find out the maximum power from the wind turbine. Then, the fitness function is evaluated to the input parameters. Here, the maximum value of power is taken as a fitness function is given as equation (6),

$$
\text { Fit }=\max \left(P_{m}\right)
$$

Where, Fit $=\max \left(P_{m}\right)$ is the fitness function of ACO algorithm, $P_{m}$ is the maximum power from the wind turbine. The ACO makes use of agents, called ants, which mimic the behavior of real ants in how they manage to establish shortest- route paths from their colony to feeding sources and back. Ants communicate information through pheromone trails, which influence which routes the ants follow, and eventually lead to a solution route [29].

Initially, The ACO was designed to solve the Traveling Salesman Problem (TSP). In the TSP, a given set of $\mathrm{n}$ cities has to be visited exactly once and the tour ends in the initial city. We call $d_{i j}(i, j=1,2, \ldots, n)$ the length of the path between cities $i$ and $j$. In the case of Euclidean TSP, $d_{i j}$ is the Euclidean distance between $i$ and $j$ is given as equation (7),

$$
d_{i j}=\left\|x_{i}-x_{j}\right\|^{2}
$$


The cities and routes between them can be represented as a connected graph $(n, E)$, where $n$ the set of towns and $E$ is the set of edges between towns (a fully connected graph in the Euclidean TSP) [30]. The ants move from one city to another following the pheromone trails on the edges. Let $\tau_{i j}(t)$ be the trail intensity on edge $(i, j)$ at iteration $t$. Then, each ant $k(k=1,2, \ldots, m)$ chooses the next city to visit depending on the intensity of the associated trail. When the ants have completed their city tours, the trail intensity is updated according to equation (8),

$$
\tau_{i j}(t+1)=\rho \cdot \tau_{i j}(t)+\Delta \tau_{i j}, t=1,2, \ldots, T
$$

Where, $\rho$ is a coefficient such that $(1-\rho)$ represents the evaporation of trail between iteration $t$ and $t+1, T$ is the total is the number of iterations (generation cycles) the trail intensity is given as equation (9),

$$
\Delta \tau_{i j}=\sum_{k=1}^{m} \Delta \tau^{k}
$$

Where, $\tau_{i j}^{k}$ is the quantity per unit of length of trail substance (pheromone in real ants) laid on edge $(i, j)$ by the $k^{\text {th }}$ ant between iteration $t$ and $t+1$.An ant $k$ at city $i$ chooses the city $j$ to go to with a probability $p_{i j}^{k}(t)$, which is a function of the town distance and of the amount of pheromone trail present on the connecting edge. The probability function is given as equation (10),

$$
p_{i j}^{k}(t)=\left\{\begin{array}{cc}
\frac{\left[\tau_{i j}(t)\right]^{\alpha} \cdot\left[\eta_{i j}\right]^{\beta}}{\sum_{k \in U}\left[\tau_{i k}(t)\right]^{\alpha} \cdot\left[\eta_{i k}\right]^{\beta}} & \forall_{j} \in U_{k} \\
0 & \text { otherwise }
\end{array}\right.
$$

Where, $U_{k}$ is a set of the cities can be chosen by the $k^{\text {th }}$ ant at city $i$ for the next step, $\eta_{i j}=1 / d_{i j}$ is a heuristic function which is defined as the visibility of the path between cities $i$ and $j$; parameters $\alpha$ and $\beta$ determine the relative influence of the trail information and the visibility [31]. The flow diagram of the proposed ACO algorithm is presented in figure 3 .

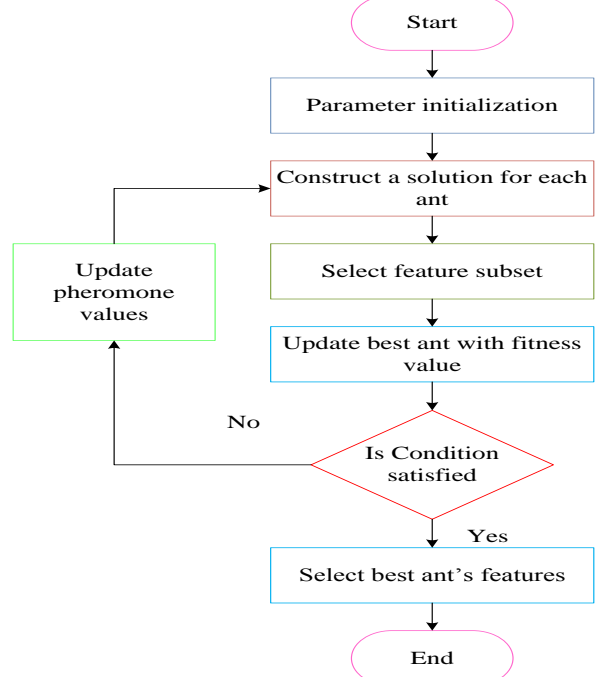

Figure 3. The flow diagram of the proposed ACO algorithm 


\section{Steps for the Proposed ACO Algorithm}

Step 1: Initiation. The amount of the pheromone on each side is initiated into a tiny constant value; allocate $m$ ants randomly to $n$ cities.

Step 2: In ACO, the pseudorandom proportional rule is used, the probability for an ant to move from city $i$ to city $j$ depends on a random variable $q$ uniformly distributed over $[0,1]$, and a predefined parameter $q_{0}$. However, the random value is described as equation (11),

$$
j=\left\{\begin{array}{c}
\arg _{i j}^{\max }(i)\left\{\tau_{i j}^{\alpha}, \eta_{i j}^{\beta}\right\} \\
J \quad \text { if } q \leq q_{0} \\
\text { otherwise }
\end{array}\right.
$$

Here, $j$ is a random variable determined in accordance with above equations. This strategy obviously increases the variety of any searching, thus avoiding any premature falling into the local optimal solution and getting bogged down.

Step 3: The local pheromone update is performed by all the ants after each construction step. Each ant applies it only to the chosen city is given as equation (12),

$$
\tau_{i j}(t+1)=(1-\rho) \cdot \tau_{i j}(t)+\rho \tau_{0}
$$

Where, $0<\rho \leq 1$ is a decay parameter, $\tau_{0}=1 / n . L_{n n}$ is the initial values of the pheromone trails, $n$ is the number of cities in the TSP and $L_{n n}$ is the cost produced by the nearest neighbor heuristic. The probability equation is mainly to avoid very strong pheromone paths to be chosen by other ants and to increase the explorative probability for other paths. Once the edge between city $i$ and city $j$ has been visited by all ants, the local updating rule makes pheromone level diminish on the edge. So, the effect of the local updating rule is to make an already edge less desirable for a following ant.

Step 4: Computing of the optimal path. After $m$ ants have travelled through all the cities, compute the length of the optimal.

Step 5: Global updating of pheromone. After all the ants have travelled through all the cities, update only the amount of the pheromone on the optimal path with equation (13) and (14),

$$
\begin{aligned}
& \tau_{i j}(t+1)=(1-\rho) \cdot \tau_{i j}(t)+\rho \cdot \Delta \tau_{i j}(t) \\
& \Delta \tau_{i j}(t)=\left\{\begin{aligned}
1 / L_{g b} & \text { if }(i, j) \in G^{\text {best }} \\
0 & \text { otherwise }
\end{aligned}\right\}
\end{aligned}
$$

Where, $\rho$ is constant and $L_{g b}$ is the length of global best tour.

Step 6: If the designated search number is not attained, then repeat the above steps.

To vary the parameters are based on our requirements and get the improved performance of the algorithm. From the proposed algorithm the pitch angle is controlled and the maximum power is reached with the maximum iteration. Then the power is transmitted to the grid connecter power system through HVDC link.

\section{HVDC Functionalities for Power Transmission}

During the state of power exchange in interconnected lines to a substation under variable or constant power, the HVDC converters comprehends the power conversion and later stabilizes the voltage through the lines giving a break even margin in the power transmission. The operation of HVDC filters any system harmonics developed in the network and improves the 
power transmission to the receiving end by independently adjusting the real and reactive power control. The significance of HVDC controller considered as part of UPFC device is a structure of the back-to-back converter that governs the conversion of ac-dc-ac. HVDC is assigned for frequency and phase independent short or long distance overhead or underground bulk power transmission with high speed controllability [32]. This provides greater real power transmission and less maintenance. It reduces the chances of installing power cables especially in difficult transmission that travels under water. By making use of the back-to-back converters, power transmission under non-synchronous ac systems is easily adaptable. The installation of HVDC also depends on the dc voltage and current ratings desired in the network that Yields for optimum converter cost. The DC overhead lines or cables are linked to AC buses and network. The operation of HVDC is restricted when network system contains low short circuit ratios. Therefore, insulation in the HVDC is essential in such cases. However, this does not restrict the converter stations operation [33]. The HVDC insulation must withstand the stress produced in ac and dc voltages to allow full operation of HVDC in the lines.

\section{E. Power Flow Analysis of UPFC Model}

Generally, UPFC is the best effect on efficient steady state transmission. Because of its design and working principle it's having such technology. This technology is settling effect on steady state, dynamic and transient stabilities. The major components of UPFC are two AC/DC converters, series and shunt transformer and the capacitor. One AC/DC converter is connected in series along the transmission line over a series. And the other is connected parallel with the transmission line through shunt transformer. The DC output side of the both converters is connected with the capacitor. This capacitor gives DC voltage for the converter operation [34]. The two voltage source converters of the UPFC, connected through a D.C link can be modeled as two ideal voltage sources, one connected in series and the other in shunt between the two buses. The output of the series voltage source $V_{s e}$ and $\theta_{s e}$ are controllable magnitude and angle between the limits $V_{s e}^{\max } \leq V_{s e} \leq V_{s e}^{\min }$ and $0 \leq \theta_{s e} \leq 2 \pi$ respectively and of the shunt voltage source is $V_{s h}$ and $\theta_{s h}$ controllable between the limits $V_{s h}^{\max } \leq V_{s h} \leq V_{s h}^{\min }$ and $0 \leq \theta_{s h} \leq 2 \pi . Z_{s e}$ and $Z_{s h}$ are the impedances of the two coupling transformer one connected in series and other in shunt between the line and the UPFC. The equivalent circuit of this model is depicted in figure 4 . The series and parallel voltages are given by equation (15) and (16),

$$
\begin{aligned}
& V_{s e}=V_{s e}\left(\cos \left(\theta_{s e}\right)+j \sin \left(\theta_{s e}\right)\right) \\
& V_{s h}=V_{s h}\left(\cos \left(\theta_{s h}\right)+j \sin \left(\theta_{s h}\right)\right)
\end{aligned}
$$

Where, $V_{c r}\left(V_{c r}^{\min } \leq V_{c r} \leq V_{c r}^{\max }\right)$ and $\theta_{c r}\left(0 \leq \theta_{c r} \leq 2 \pi\right)$ are voltage magnitude and adjustable angle of series voltage resource. The voltage magnitude and equivalent angle $\left(v_{v r}, \theta_{v r}\right)$ designate the equivalent voltage source limitation [35].

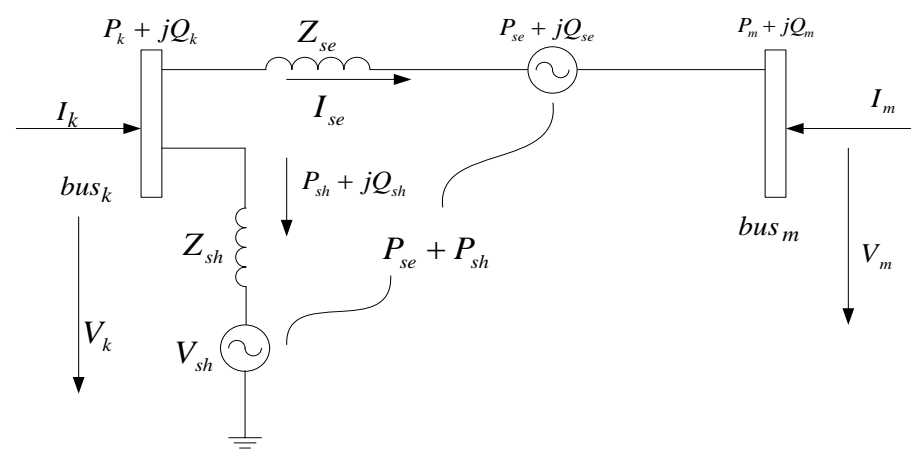

Figure 4. The equivalent diagram of UPFC 
The input system data includes the basic system data needed for conventional power flow calculation consisting of the number and types of buses, transmission line data, generation and load data, location of UPFC and the control variables of UPFC i.e the magnitude and angles of voltage output $V_{s e}$ and $V_{s h}$ of two converters. The inclusion of the UPFC increases one bus in the system. The UPFC power equations are combined with the network equations to give equation (17),

$$
P_{i}+j Q_{i}=\sum_{j=1}^{n} V_{i}, V_{j} Y_{i j} \angle\left(\theta_{i j}-\delta_{i}+\delta_{j}\right)+P_{i}^{\prime}+j Q_{i}^{\prime}
$$

Where, $P_{i}^{\prime}+j Q^{\prime}$ is active and reactive power flow due to UPFC between the bus $k$ and $m . P_{i}+j Q_{i}$ denotes active and reactive power at the $i^{t h}$ bus. $V_{i} \angle \delta_{i}$ refers voltage and angle of $i^{\text {th }}$ bus, $V_{j} \angle \delta_{j}$ refers Voltage and angle of $j^{\text {th }}$ bus. $Y_{i j}$ is a admittance of the transmission line between the bus $i$ and $j$. The power flow constraint of the UPFC is included in the jacobian. The inclusion of these variables increases the dimension of the jacobian. The power equations are mismatched until convergence is achieved. A scalar multiplier is used to control the updating of variables to ensure that they converge in an optimal way to the solution point. The real and reactive powers of the particular bus are described in the following equations (18) and (19).

$$
\begin{aligned}
& P_{i}=V_{i} V_{j} \sum_{n=1}^{N B} G_{i j} \cos \delta_{i j}+B_{i j} \sin \delta_{i j} \\
& Q_{i}=V_{i} V_{j} \sum_{n=1}^{N B} G_{i j} \sin \delta_{i j}-B_{i j} \cos s \delta_{i j}
\end{aligned}
$$

Where, $V_{i}$ and $V_{j}$ symbolize the voltage of $i$ and $j$ buses respectively, $N B$ is the total number

of buses, $\delta_{i j}$ is the angle between $i$ and $j$ buses respectively, $G_{i j}$ and $B_{i j}$ is the conductance and susceptance values respectively.

At this moment the complete scheme of UPFC is proficient of mutually delivering and captivating actual and immediate power from the scheme. The power stability among the series and shunt converter is a prerequisite to maintain a constant voltage transversely the DC capacitor. The power flow capability and temporary constancy are enhanced by series division of UPFC which insert the voltage of variable magnitude and phase angle. These series division can replace actual power among a broadcast line to develop above said eminence of broadcast line. The shunt division of UPFC scheme is replaces a current and power factor angle of convenient magnitude through the power scheme [36]. It is normally prohibited to stability the actual power combination or insertion into the power scheme by the series division, in addition the wounded by changeable the DC voltage at the preferred value.

\section{F. UPFC Enhancement with aid of ANFIS}

ANFIS is an adaptive network that is generally corresponding to a fuzzy presumption scheme, where the productivity has been attained by utilizing fuzzy regulations on inputs. An ANFIS scheme is a mixture of neural network and fuzzy scheme in such a manner that neural network is utilized to resolve the limitation of fuzzy scheme. A neural network is employed to mechanically change the scheme limitation. The ANFIS is a very dominant method for forming nonlinear and compound scheme through less input and output preparation data through quicker learning and high exactness. The neuro-fuzzy scheme through the learning competence of neural network and by the compensation of the rule-base fuzzy scheme can develop the presentation considerably and can supply a system to integrate precedent explanation into the categorization procedure [37]. In neural network the preparation fundamentally constructs the 
scheme. Though, utilizing a neuro fuzzy format, the scheme is constructed by fuzzy logic description and is after that distinguished by neural network preparation algorithms.

\section{Architecture of ANFIS}

The representation method utilized by ANFIS is comparable to numerous scheme recognition procedures. Initially, a parameterized representation arrangement (connecting inputs to association utility to regulated outputs to association task, and so on) is assumed. After that input/output data is composed in a structure that will be functional by ANFIS for preparation. ANFIS can subsequently be utilized to guide the FIS representation to follow the preparation data obtainable to it by altering the association task limitation along with an elected mistake principle. Function of ANFIS looks like feed-forward back propagation network. Resultant limitations are considered onward whereas basis limitations are intended backward. There are two learning process in neural segment of the scheme: Hybrid learning process and back-propagation learning process. In fuzzy segment, only zero or primary order Sugeno inference scheme or Tsukamoto presumption scheme can be utilized. This segment initiates the fundamentals of ANFIS network design and its hybrid learning regulation [38]. The Sugeno fuzzy model was proposed by Takagi, Sugeno, and Kang in an effort to formalize a systematic approach to generating fuzzy rules from an input-output dataset. The propose technique objective function is evaluated by equation (20),

$$
F=\operatorname{Min}(E)=\operatorname{Min}\left\{P^{r e f}-P^{a c t}\right\}
$$

Where, $E$ is the error value between the reference and actual powers $P^{r e f}$ and $P^{a c t}$ represent the reference and actual values of power. The ANFIS structure of two input one output is depicted in figure 5. The two inputs are error $E$, change in error $\Delta E$ and power variation output. The change in error is estimated as equation (21),

$$
\Delta E=E(s)-E(s-1)
$$

Where, $E(s-1)$ is the previous state of error, In this connected structure, the input and output nodes represent the training values and the predicted values, respectively, and in the hidden layers, there are nodes functioning as membership functions (MFs) and rules. This architecture has the benefit that it eliminates the disadvantage of a normal feed forward multilayer network, where it is difficult for an observer to understand or modify the network. Here $E, \Delta E$ are inputs, $Y$ is output, the circles represent fixed node functions and squares represent adaptive node functions. Consider a first order Sugeno-fuzzy inference system which contains two rules:

Rule 1: If $E$ is $A 1$ and $\Delta E$ is $B 1$; then $f_{1}=p_{1} E+q_{1} \Delta E+r_{1}$

Rule 2: If $E$ is $A 2$ and $\Delta E$ is $B 2$; then $f_{2}=p_{2} E+q_{2} \Delta E+r_{2}$

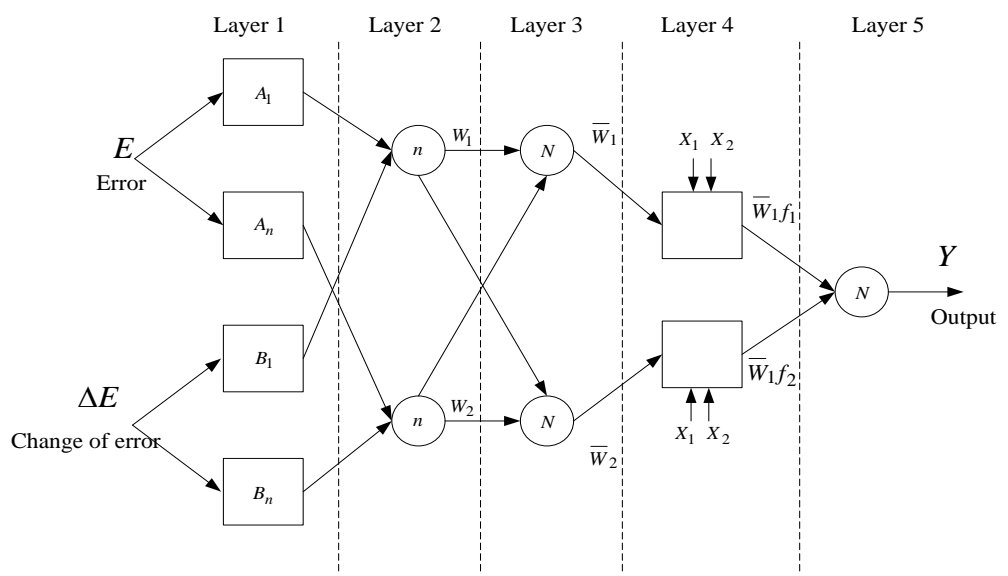

Figure 5. The controlling structure of ANFIS 
At this point, $p_{1}, p_{2}, q_{1}, q_{2}, r_{1}$ and $r_{2}$ are linear limitation and $A 1, A 2, B 1$ and $B 2$ are nonlinear limitation. ANFIS is an execution of a fuzzy logic presumption scheme through the structural design of a five-layer feed-forward network. The scheme structural design contains five layers, i.e., fuzzy layer, product layer, normalized layer, de-fuzzy layer and total output layer. By this manner ANFIS utilize the compensation of learning competence of neural networks and presumption system related to human brain offered by fuzzy logic.

The projected ANFIS structural design contains five layers in which circle shaped nodes are described as fixed nodes, which means the node limitation are autonomous on the further nodes and square shaped nodes are described as adaptive nodes, whose node limitation rely on the supplementary nodes [39].

Layer 1: Quantity of nodes in this level symbolizes the quantity of fuzzy sets utilized. The first layer nodes are in square shaped and limitations of these nodes significant the association task. In this study work, a triangular association task is utilized as equation (22),

$$
O_{1 i}=\mu_{A i}(E) ; O_{2 i}=\mu_{B i}(\Delta E) ; i=1,2, \ldots, 5
$$

Here, $E$ and $\Delta E$ are the two inputs, $A i$ and $B i$ are the fuzzy sets corresponding to the node $i . O_{1 i}$ and $O_{2 i}$ are membership functions of fuzzy set $A i$ and $B i$. Generalized bell membership function is popular method for specifying fuzzy sets because of their smoothness and concise notation is defined as equation (23),

$$
\mu_{A i}(E)=\frac{1}{1+\left|\frac{E-c_{i}}{a_{i}}\right|^{2 b_{i}}}
$$

Now, $a_{i}, b_{i}$ and $c_{i}$ is the limitation group of the association task. The center and width of the association task is diverse by regulating $c_{i}$ and $a_{i}$. The limitation $b_{i}$ is utilized to direct the slopes at the intersect points.

Layer 2: In this level, nodes are recognized as regulation nodes. Each node increases the inward signals and offer the product that signify the weight $(w i)$ of a regulation and is specified by equation (24),

$$
w i=\mu_{A i}(E) \mu_{B i}(\Delta E) ; i=1,2, \ldots, 5
$$

Layer 3: In this layer, weights are normalized as equation (25),

$$
\bar{w}_{i}=\frac{w_{i}}{w_{i}+w_{1}} ; i=1,2
$$

Layer 4: Generally, the measurement of this level resolves the integer of fuzzy regulations utilized in the scheme. For each node of this level, output(Y) is specified by equation (26),

$$
Y=\bar{w}_{i} f_{i}
$$

Where, $f_{i}=p_{i} E+q_{i} \Delta E+r_{i}$ and $\bar{w}_{i}$ is the standardized weight of $i^{\text {th }}$ node. $p_{i}, q_{i}$ and $r_{i}$ are the intended limitation that are resolute throughout the preparation procedure and $i$ is the quantity of association task of particular input.

Layer 5: In the final layer, the overall output is computed by adding all the outputs of the previous layer. The single fixed node calculates the overall output as the summation of all incoming signals as equation (27), 


$$
\sum_{i} \bar{w}_{i} f_{i}=\frac{\sum_{i} w_{i} f_{i}}{\sum_{i} w_{i}}
$$

It can be experimental that there are two adaptive levels in this ANFIS structural design, i.e. the first level and the fourth level [40]. The projected regulator is verified in MATLAB/ANFIS editor tool box among a triangular association task as it suggests smallest preparation fault. Because, the back propagation algorithm is disreputable for its lateness and inclination to develop into fascinated in limited minima, a fusion learning algorithm is utilized in this donation. This algorithm is quick and precise in recognize the limitation.

\section{Results and Discussions}

In this section, we discussed about the performance analysis of the proposed technique and compared with some different techniques like GA and PSO. The proposed technique is applied with Intel(R) core(TM) i5 processor, 4GB RAM and MATLAB/Simulink 7.10.0 (R2015a) platform. The Simulink model of the proposed system is illustrated in the figure 6 , which shows the small signal stability model with the MG connected load system is controlled based on the proposed technique. The proposed ACO algorithm is used to gather the maximum power from the WECS and ANFIS is used to control the power flow of the gird connected power system with the help of UPFC.
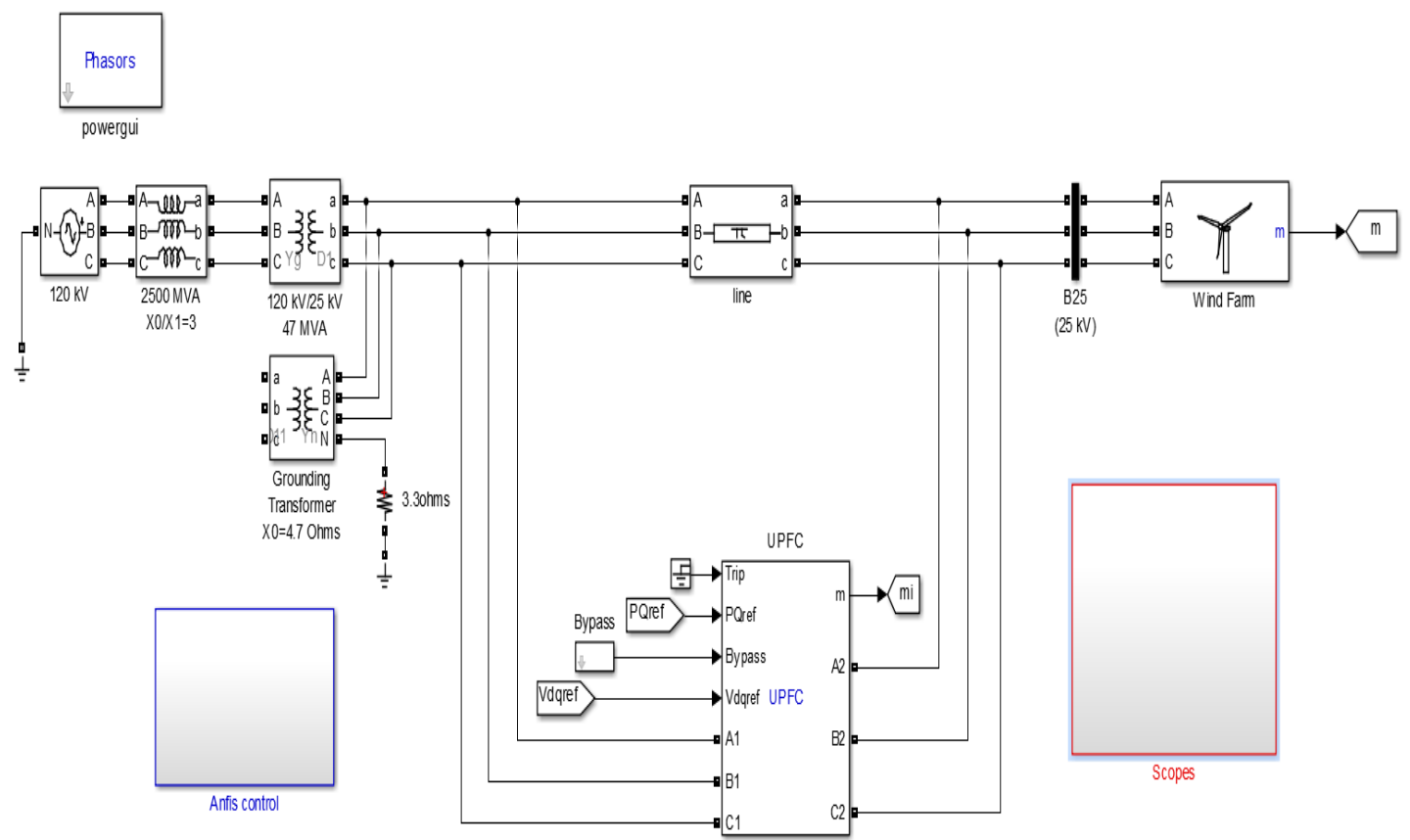

Figure 6. The Simulink model of the proposed system 
Sunny Vig, et al.

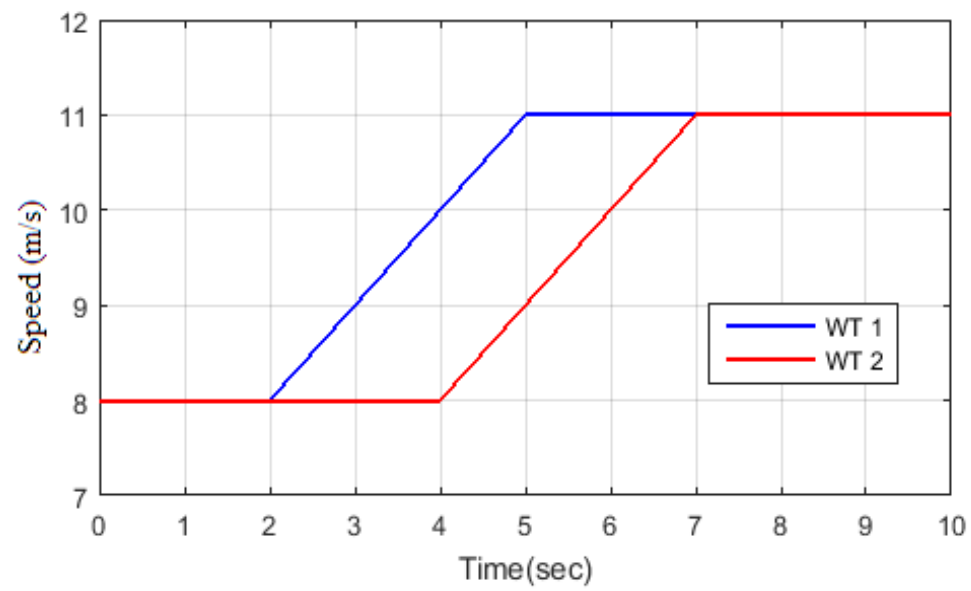

(i)

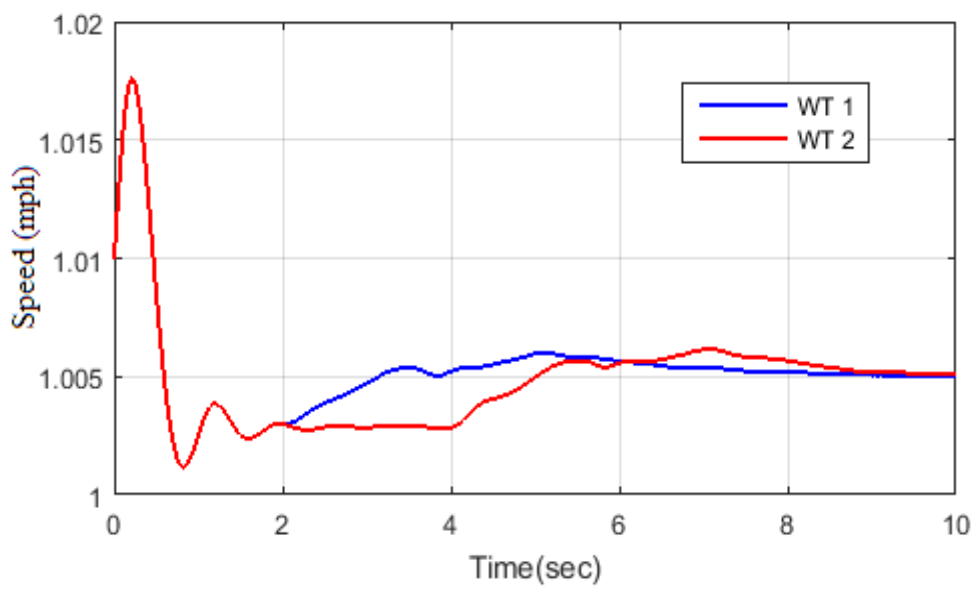

(ii)

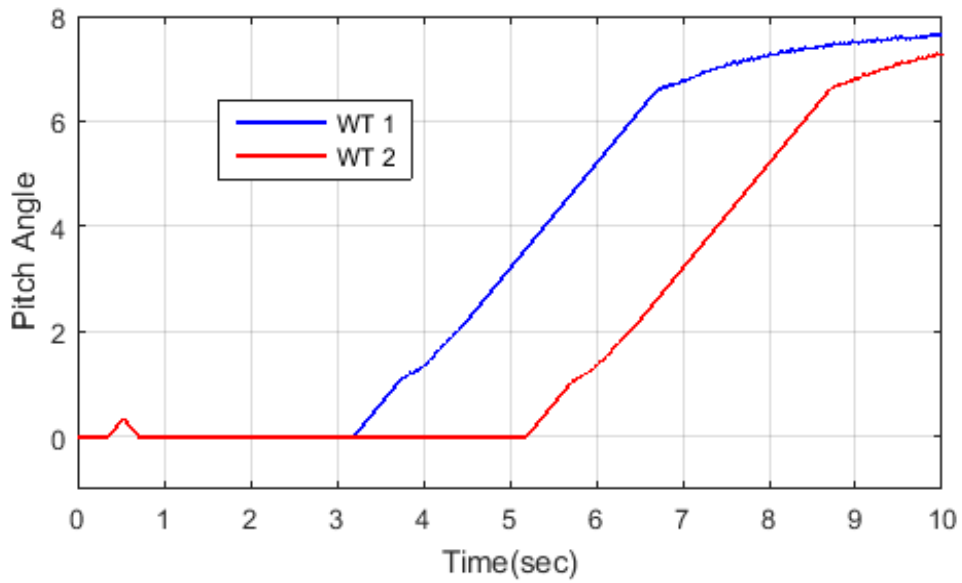

(iii) 


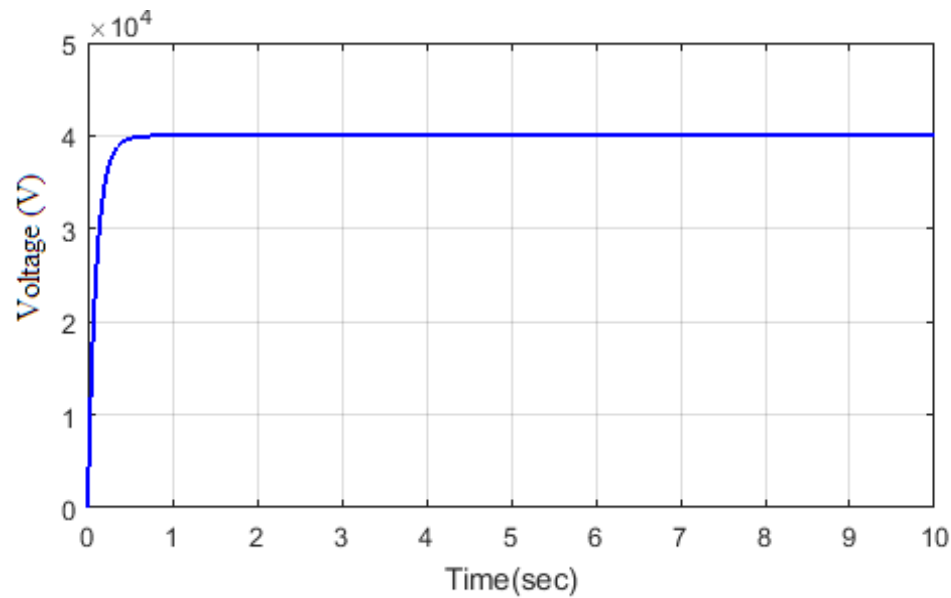

(iv)

Figure 7. Performance analysis of wind energy conversion parameters (i) wind speed, (ii) wind turbine rotor speed, (iii) pitch angle, (iv) HVDC link voltage

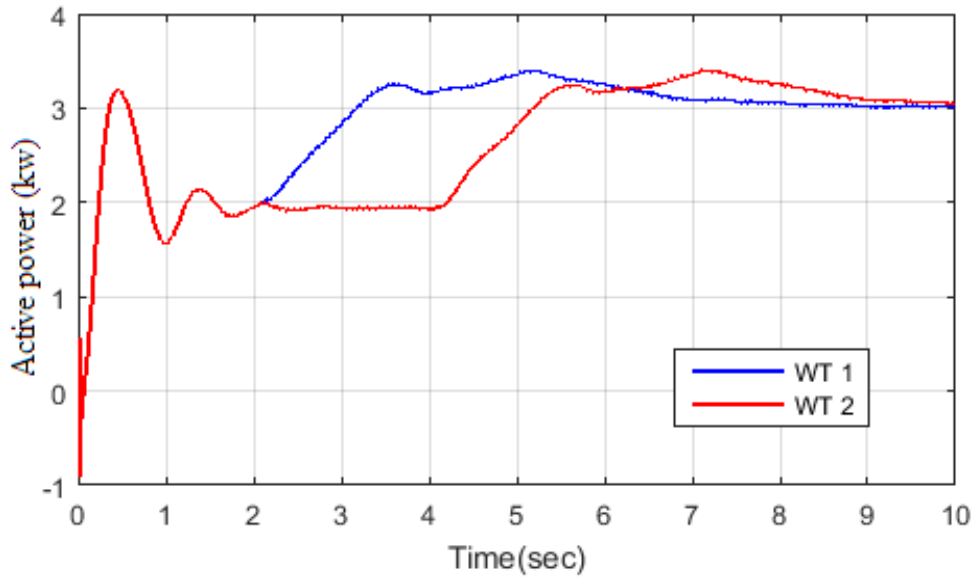

(a)

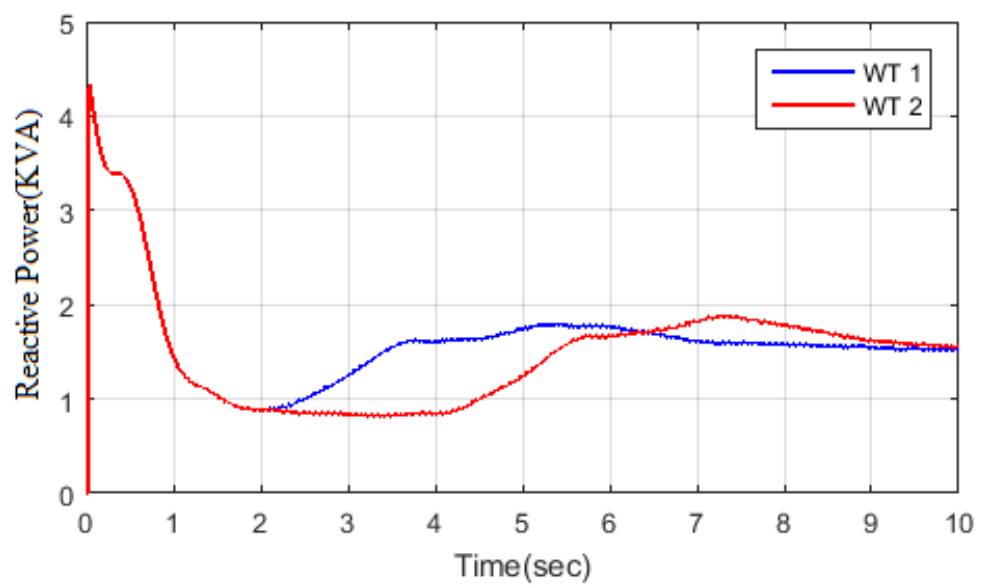

(b) 


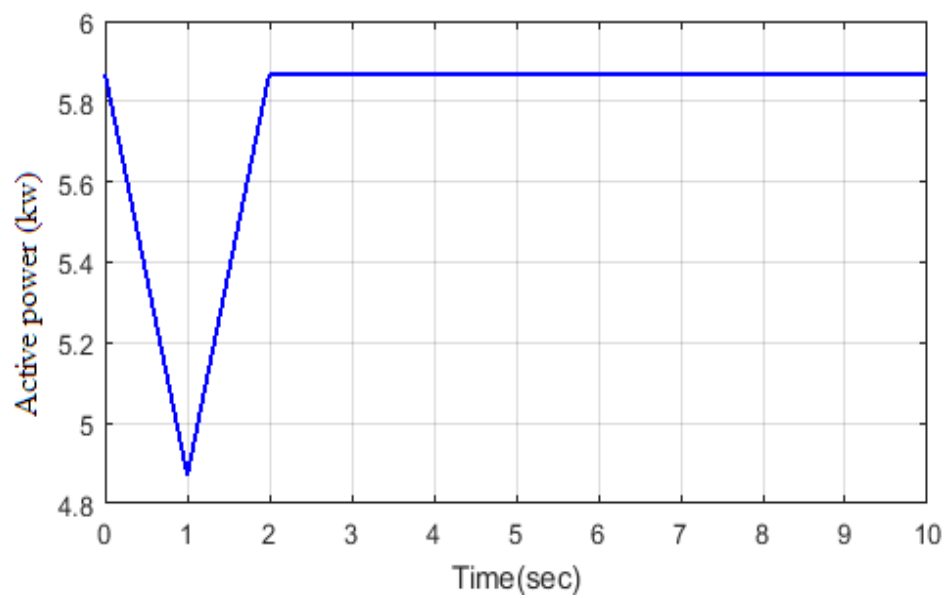

(c)

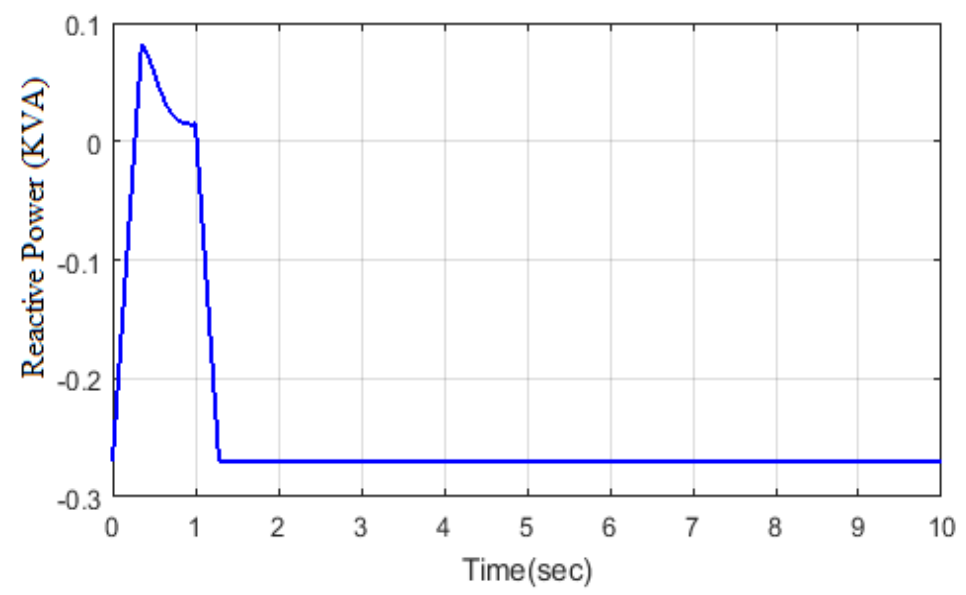

(d)

Figure 8. Power performance of (a) active power, (b) reactive power of wind and (c) active power, (d) reactive power of UPFC model

The performance of the WECS generated power is based on the speed of the wind turbine, so to control the wind turbine speed only to get the adequate power from the WECS. Based on the wind speed the WECS is generated the power, to improve the PQ to controls the pitch angle of the wind turbine rotor for stable power generation. The measured wind speed, turbine speed, pitch angle and the output HVDC link voltage are illustrated in figure 7. Then the generated power transmitted to grid using the HVDC link and UPFC. The active and reactive power of the WECS and UPFC is described in a figure 8. 


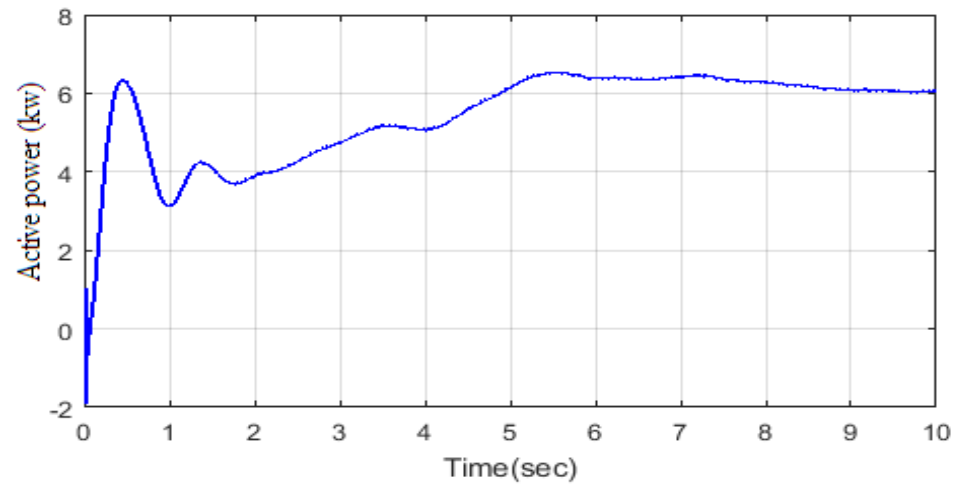

(i)

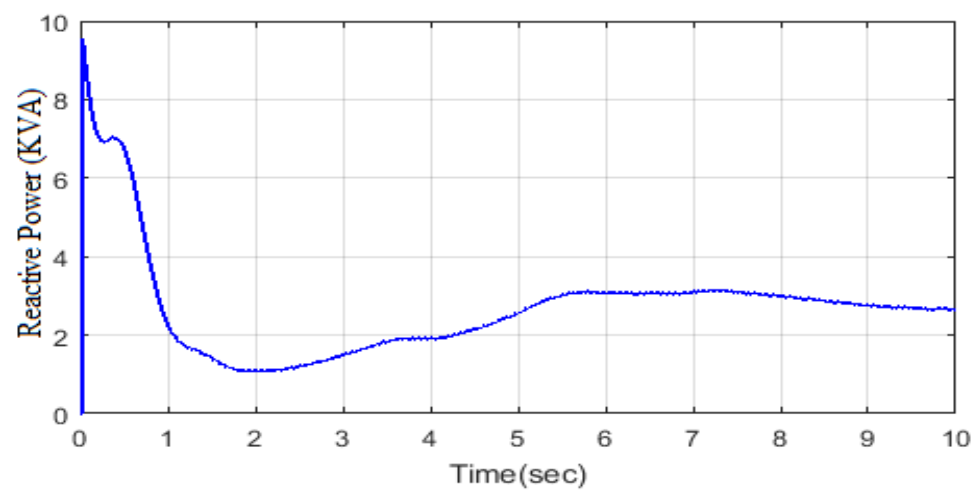

(ii)

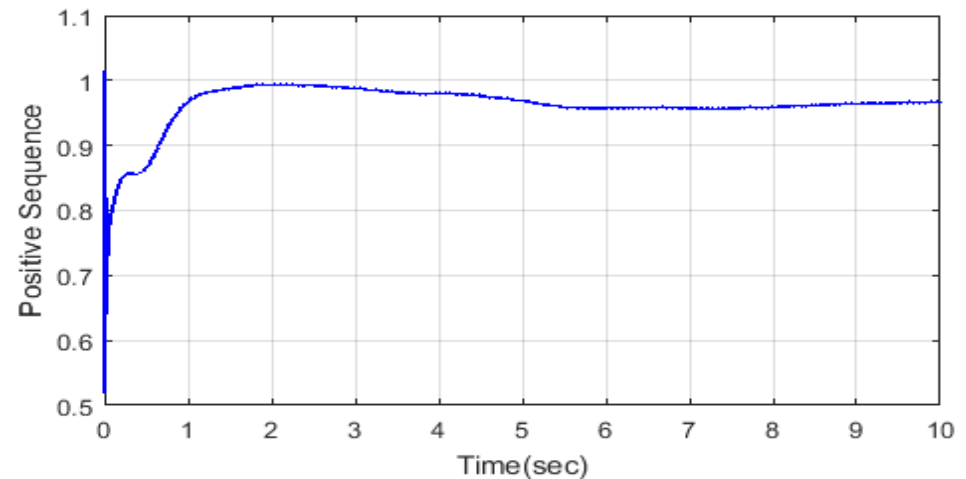

(iii) 
Sunny Vig, et al.

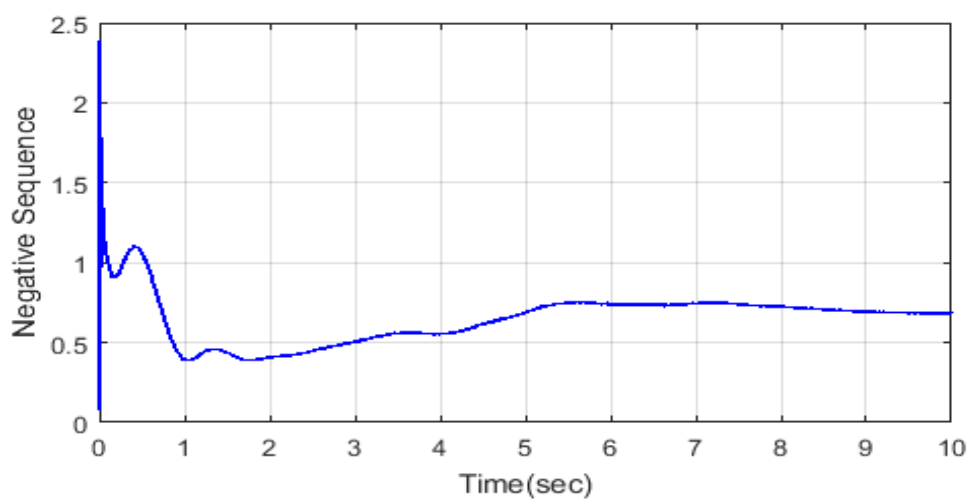

(iv)

Figure 9. The grid power performance with (i) active power (ii) reactive power, (iii) positive sequence and (iv) negative sequence of grid connected wind power system

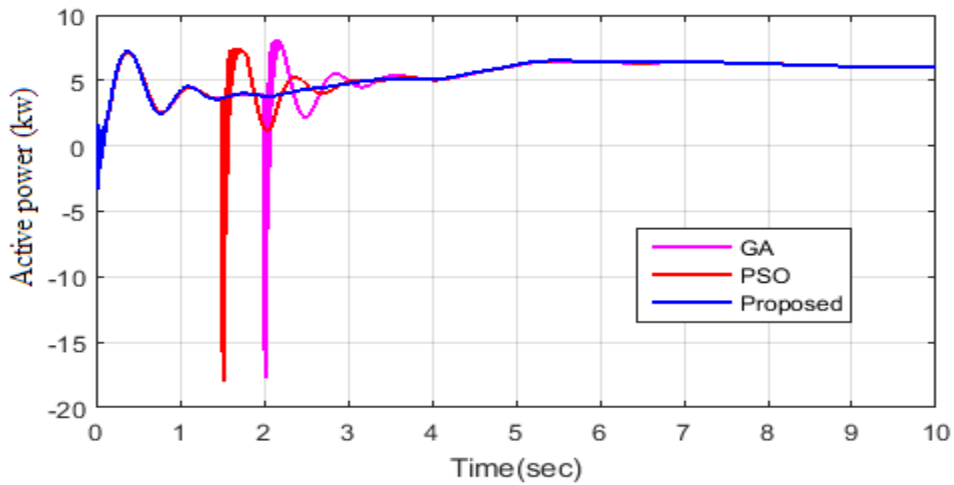

(a)

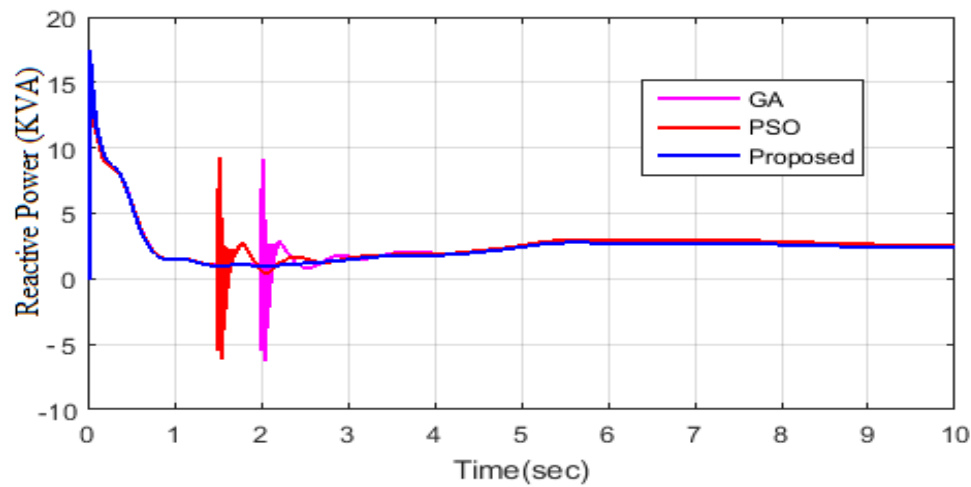

(b) 


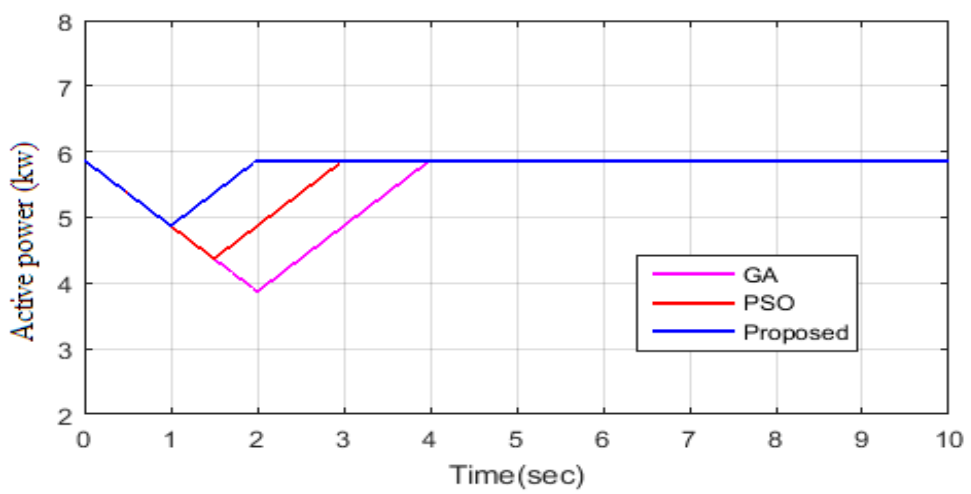

(c)

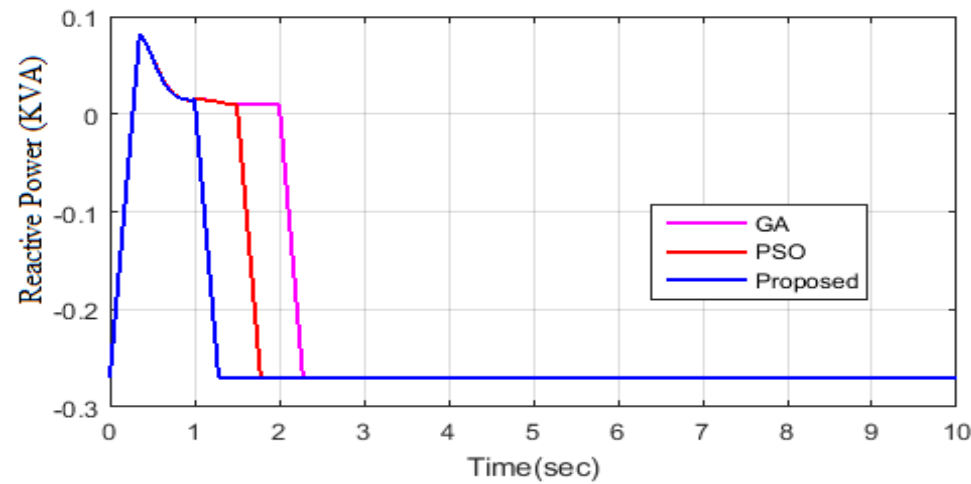

(d)

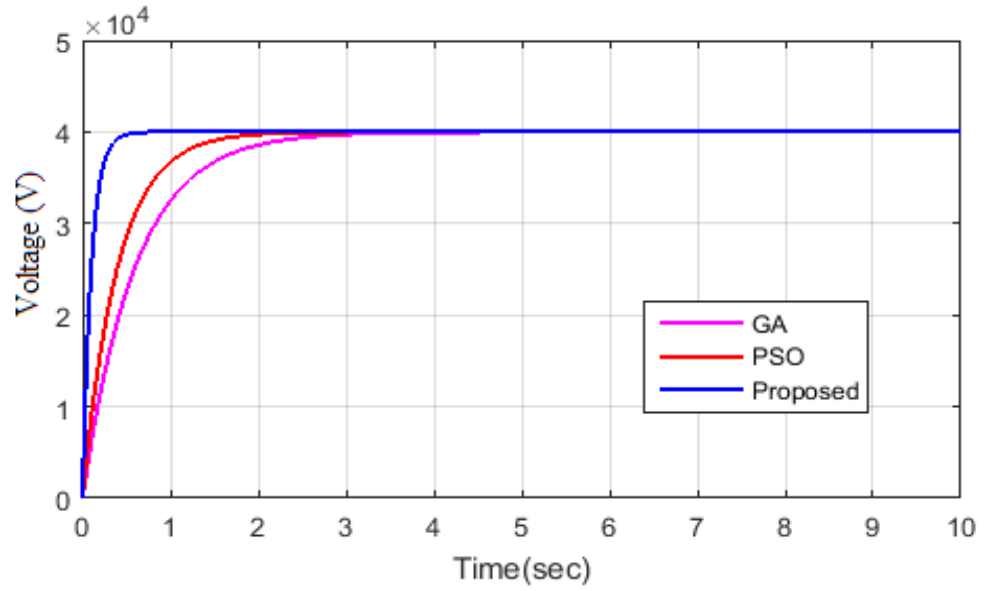

(e)

Figure 10. Comparison analysis of grid (a) active power, (b) reactive power, (c) active power, (d) reactive power of the UPFC and (d) the HVDC link voltage

The wind turbine model is generates the active power based on the wind speed and the rotor angle of the turbine. To control the pitch angle of the wind turbine is gathering the maximum and linear power from the power system. The generated power is transmitted to grid based on the HVDC link. The active and reactive power of the grid connected proposed system is figure 9. Which is also stabilizing the output power for gathered the stabilized power. 
Finally, to prove the efficiency of the proposed technique is compared with some existing techniques like GA and PSO. The comparisons of the techniques are performed in a grid side and UPFC. To measure the active and reactive power of the grid and UPFC and the HVDC link voltage is described in figure 10. The comparison is based on the grid active and reactive power and UPFC real and reactive power of the proposed system. Then the HVDC link voltage is reached the stable position within $0.05 \mathrm{sec}$.

From the above the observed results, the proposed ACO based WECS and ANFIS based UPQC controller achieves better performance for compensating the PQ. The dc bus voltages are almost maintained to the reference value under all disturbances. To improve the performance of the proposed system is to stabilize the power flow of the grid connected system.

\section{Conclusion}

In this paper presented an optimal reactive power dispatch (ORPD) technique with WECS and UPFC for required power deliver to the grid connected power system. In this proposed technique utilized the ACO algorithm and ANFIS controller for improving the steady state stability of the power system. The ACO algorithm is utilized for gathering maximum power from the WECS. Based on the algorithm is control the pitch angle of the wind turbine model for extracting maximum power from the WECS. The maximum generated power is transmitted through HVDA link to grid connected power system. To optimizing the output power of the system is based on the UPFC, which is control active and reactive flow of power in a HVDC transmission line. The ANFIS controller is employed to enhance the performance of the UPFC. The UPFC optimized the variations of the actual power and reference power of the grid connected power system. The proposed optimization problem is solved utilizing ACO and ANFIS approach, which is employed to decide the finest compromise solution. The proposed method is implemented in MATLAB/Simulink platform and tested with the different wind speed condition. To verify the effectiveness and optimality of the proposed model, the obtained results in the deterministic case is compared with the existing methods like GA and PSO.

\section{Reference}

[1]. S.G. Bharathi Dasan, Sharon Ravichandran Kamesh and R.P. Kumudini Devi, "Steadystate analysis of Grid connected WECS using FACTS controller", In proceedings of IEEE conference on Emerging Trends in Electrical and Computer Technology, pp. 127-132, 2011

[2]. Dipesh Kumar and Kalyan Chatterjee, "A review of conventional and advanced MPPT algorithms for wind energy systems", An International Journal of Renewable and Sustainable Energy Reviews, Vol. 55, pp. 957-970, 2016

[3]. Yasser M. Alharbi, A. M. Shiddiq Yunus and A. Abu Siada, "Application of UPFC to Improve the FRT Capability of Wind Turbine Generator ", An International Journal of Electrical Energy, Vol. 1, No. 4, pp. 188-193, 2013

[4]. Yazhou Lei, Alan Mullane, Gordon Lightbody and Robert Yacamini, "Modeling of the wind turbine with a doubly fed induction generator for grid integration studies", IEEE transactions on energy conversion, Vol. 21, No. 1, pp. 257-264, 2006

[5]. Beltran, Brice, Tarek Ahmed-Ali and Mohamed El Hachemi Benbouzid, "Sliding mode power control of variable-speed wind energy conversion systems", IEEE Transactions on Energy Conversion, Vol. 23, No. 2, pp. 551-558, 2008

[6]. Frede Blaabjerg, Remus Teodorescu, Marco Liserre and Adrian V. Timbus, "Overview of control and grid synchronization for distributed power generation systems", IEEE Transactions on industrial electronics, Vol. 53, No. 5, pp. 1398-1409, 2006

[7]. Snehaprava Swain and Pravat Kumar Ray, "Short circuit fault analysis in a grid connected DFIG based wind energy system with active crowbar protection circuit for ride through 
capability and power quality improvement", An International Journal of Electrical Power and Energy Systems, Vol. 84, pp. 64-75, 2017

[8]. GM Joselin Herbert, Selvaraj Iniyan, E. Sreevalsan and S. Rajapandian, "A review of wind energy technologies", An International Journal of Renewable and sustainable energy Reviews, Vol. 11, No. 6, pp. 1117-1145, 2007

[9]. Ken Weng Kow, Yee Wan Wong, Rajparthiban Kumar Rajkumar and Rajprasad Kumar Rajkumar, "A review on performance of artificial intelligence and conventional method in mitigating PV grid-tied related power quality events", An International Journal of Renewable and Sustainable Energy Reviews, Vol. 56, pp. 334-346, 2016

[10]. M. Ramesh and A. Jaya Laxmi, "Enhancement of Power Transmission Capability of HVDC System using Facts Controllers", An International Journal of Advances in Engineering and Technology, Vol. 1, No. 5, pp. 401-416, 2011

[11]. N. Senthil kumar and J. Gokulakrishnan, "Impact of FACTS controllers on the stability of power systems connected with doubly fed induction generators", An International Journal of Electrical Power and Energy Systems, Vol. 33, No. 5, 1172-1184, 2011

[12]. Chen, Zhe, "Issues of connecting wind farms into power systems", In proceedings of IEEE conference on Transmission and Distribution Conference and Exposition, pp. 1-6, 2005

[13]. Marco Dorigo and Thomas Stützle, "The ant colony optimization metaheuristic: Algorithms, applications, and advances", Handbook of metaheuristics, pp. 250-285, 2003

[14]. Gomis-Bellmunt, Oriol, Adria Junyent-Ferre, Andreas Sumper and Joan Bergas-Jane, "Control of a wind farm based on synchronous generators with a central HVDC-VSC converter", IEEE Transactions on power systems, Vol. 26, No. 3, pp. 1632-1640, 2011

[15]. Om Prakash Mahelan and Abdul Gafoor Shaik, "Comprehensive overview of grid interfaced wind energygeneration systems", An International Journal of Renewable and Sustainable Energy Reviews, Vol. 57, pp. 260-281, 2016

[16]. de Almeida, Rogerio G., JA Peças Lopes and J. A. L. Barreiros, "Improving power system dynamic behavior through doubly fed induction machines controlled by static converter using fuzzy control", IEEE Transactions on Power Systems, Vol. 19, No. 4, pp. 1942-1950, 2004

[17]. Shuhui Li, Timothy A. Haskew and Ling Xu, "Control of HVDC light system using conventional and direct current vector control approaches", IEEE Transactions on Power Electronics, Vol. 25, No. 12, pp. 3106-3118, 2010

[18]. Altyeb Altaher, Ammar Almomani and Sureswaran Ramadass, "Application of Adaptive Neuro-Fuzzy Inference System for Information Security", An International Journal of Computer Science, Vol. 8, No. 6, pp. 983-986, 2012

[19]. V. Calderaro, V. Galdi, A. Piccolo and P. Siano, "A fuzzy controller for maximum energy extraction from variable speed wind power generation systems", An International Journal of Electric Power Systems Research, Vol. 78, No. 6, pp. 1109-1118, 2008

[20]. Seung-Ho Song, Shin-il Kang, and Nyeon-Kun Hahm, "Implementation and control of grid connected AC-DC-AC power converter for variable speed wind energy conversion system", In proceedings of IEEE conference on Applied Power Electronics, Vol. 1, pp. $154-158,2003$

[21]. Joan Sau-Bassols, Eduardo Prieto-Araujo, Samuel Galceran-Arellano and Oriol GomisBellmunt, "Operation and control of a Current Source Converter series tapping of an LCC-HVDC link for integration of Offshore Wind Power Plants", An International Journal of Electric Power Systems Research, Vol. 141, pp. 510-521, 2016

[22]. Fernando D. Bianchi and Jos Luis Domnguez-Garca, "Coordinated Frequency Control Using MT-HVDC Grids with Wind Power Plants", IEEE Transactions on Sustainable Energy, Vol. 7, No. 1, pp. 213-220, 2016

[23]. Chayan Bhattacharjee and Binoy Krishna Roy, "Advanced fuzzy power extraction control of wind energy conversion system for power quality improvement in a grid tied hybrid 
generation system", IET Generation, Transmission and Distribution, Vol. 10, No. 5, pp. 1179-1189, 2016

[24]. Asit Mohanty, Sandipan Patra and Prakash K. Ray, "Robust fuzzy-sliding mode based UPFC controller for transient stability analysis in autonomous wind-diesel-PV hybrid system", IET Generation, Transmission and Distribution, Vol. 10, No. 5, pp. 1248-1257, 2016

[25]. Rong Zeng, Lie Xu, Liangzhong Yao, Stephen J. Finney and Yi Wang, "Hybrid HVDC for Integrating Wind Farms with Special Consideration on Commutation Failure", IEEE Transactions on Power Delivery, Vol. 31, No. 2, pp. 789-797, 2016

[26]. M. Linus and P. Damodharan, "Maximum power point tracking method using a modified perturb and observe algorithm for grid connected wind energy conversion systems," IET Renewable Power Generation, Vol. 9, No. 6, pp. 682-689, 2015

[27]. Ali Ajami and Mehdi Armaghan, "Fixed speed wind farm operation improvement using current-source converter based UPQC", An International Journal of Energy Conversion and Management, Vol.58, pp.10-18, 2012

[28]. Ehab S. Ali, "Speed control of induction motor supplied by wind turbine via Imperialist Competitive Algorithm", An International Journal of Energy, Vol.89, pp.593-600, 2015

[29]. Abdolvahhab Fetanat and Ehsan Khorasaninejad, "Size optimization for hybrid photovoltaic-wind energy system using ant colony optimization for continuous domains based integer programming", An International Journal of Applied Soft Computing, Vol.31, pp.196-209, 2015

[30]. A.A. Mousa, Waiel F. Abd El-Wahed and R.M. Rizk-Allah, "A hybrid ant colony optimization approach based local search scheme for multiobjective design optimizations", An International Journal of Electric Power Systems Research, Vol.81, pp.1014-1023, 2011

[31]. J. Wang, J. Cao, B. Li, S. Lee and R. S. Sherratt, "Bio-inspired ant colony optimization based clustering algorithm with mobile sinks for applications in consumer home automation networks," IEEE Transactions on Consumer Electronics, Vol.61, No.4, pp.438-444, 2015

[32]. M. Ramesh and A. Jaya Laxmi, "Enhancement of Power Transmission Capability of Hvdc System Using Facts Controllers", An International Journal of Advances in Engineering and Technology, Vol.1, No.5, pp.401-416, 2011

[33]. Moawwad, M. S. El Moursi and W. Xiao, "Advanced Fault Ride-Through Management Scheme for VSC-HVDC Connecting Offshore Wind Farms," IEEE Transactions on Power Systems, Vol.31, No.6, pp.4923-4934, 2016

[34]. Vijay Kumar and N.V. Srikanth, "A hybrid approach for optimal location and capacity of UPFC to improve the dynamic stability of the power system", An International Journal of Applied Soft Computing, 2016

[35]. Reza Taghavi, Ali Reza Seifi and Haidar Samet, "Stochastic reactive power dispatch in hybrid power system with intermittent wind power generation", An International Journal of Energy, Vol.89, pp.511-518, 2015

[36]. Amin Khodabakhshian, Mohammad Reza Esmaili and Mosayeb Bornapour, "Optimal coordinated design of UPFC and PSS for improving power system performance by using multi-objective water cycle algorithm", An International Journal of Electrical Power and Energy Systems, Vol.83, pp.124-133, 2016

[37]. M. Ajay Kumar and N. V. Srikanth, "An adaptive neuro fuzzy inference system controlled space cector pulse width modulation based HVDC light transmission system under AC fault conditions", Central European Journal of Engineering, Vol.4, No.1, pp.27-38, 2014

[38]. Sedigheh Danesh, Rahman Farnoosh and Tahereh Razzaghnia, "Fuzzy nonparametric regression based on adaptive neuro fuzzy inference system", An International Journal of Neuro computing, Vol.173, No.3, pp.1450-1460, 2016 
[39]. Farid Hashemi, Noradin Ghadimi and Behrooz Sobhani, "Islanding detection for inverterbased DG coupled with using an adaptive neuro-fuzzy inference system", An International Journal of Electrical Power and Energy Systems, Vol.45, pp.443-455, 2013

[40]. Pouria Sarhadi, Behrooz Rezaie and Zahra Rahmani, "Adaptive predictive control based on adaptive neuro-fuzzy inference system for a class of nonlinear industrial processes", An International Journal of the Taiwan Institute of Chemical Engineers, Vol.61, pp.132137,2016

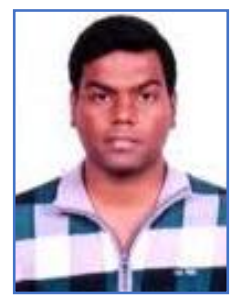

Sunny Vig obtained his Bachelor's degree Electrical Engineering from University of PTU. Then he obtained his Master's degree in Electrical Engineering from Punjab Engineering College (Deemed to be University), Chandigarh. Currently, he is pursuing his $\mathrm{PhD}$ from Punjab Engineering College (Deemed to be University), Chandigarh.

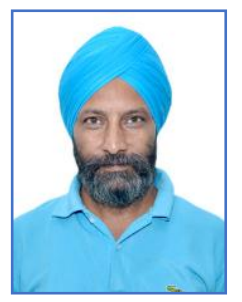

Surjan Balwinder Singh is Professor in the Electrical Engineering Department, Punjab Engineering College (Deemed to be University), Chandigarh. The author received B.E. (Electrical) in 1989, M. Tech. (Power Apparatus \& Systems) in Feb 1991, and Ph.D. degrees in 2008, from Shivaji University Kolhapur, I.I.T. Bombay, and Panjab University Chandigarh respectively. He has twenty years of professional teaching experience in the same institute. He has taught undergraduate and post graduate students. $\mathrm{He}$ has guided number of post graduate and $\mathrm{PhD}$ students to complete their thesis mainly in the field of power system stability studies also in field of photometric analysis of luminaires His areas of interest include power system stability studies, illumination engineering, machine applications, modeling and analysis. The author is member of professional societies like IEEE, Indian Society of Lighting Engineering (M), Fellow Institution of Engineers (I), Chartered Engineer IE (I). 